\title{
ORAL HEALTH-RELATED QUALITY OF LIFE IN CZECH POPULATION
}

\author{
Lenka Hodačová ${ }^{1}$, J indra Šmejkalová2, Eva Čermáková ${ }^{3}$, Radovan Slezák ${ }^{4}$, Vimal J acob², Eva Hlaváčková5 \\ 'Department of Social Medicine, Faculty of Medicine in Hradec Králové, Charles University in Prague, Czech Republic \\ 2Department of Hygiene and Preventive Medicine, Faculty of Medicine in Hradec Králové, Charles University in Prague, Czech Republic \\ ${ }^{3}$ Computer Technology Centre, Faculty of Medicine in Hradec Králové, Charles University in Prague, Czech Republic \\ ${ }^{4}$ Department of Dentristry, Faculty of Medicine in Hradec Králové, Charles University in Prague, Czech Republic \\ ${ }^{5}$ Department of Nursing, Faculty of Health Studies, University of Pardubice, Czech Republic
}

\begin{abstract}
SUMMARY
Objective: The purpose of this study was to assess the oral health-related quality of life in Czech population.

Methods: Data were collected from 1,380 subjects aged 30 to 69 years attending the Department of Dentistry, Medical Faculty of Charles University in Hradec Králové or attending three private dental practitioners collaborating on the study. Oral health-related quality of life was measured with the Oral Health Impact Profile (OHIP-14) questionnaire that was translated to $\mathrm{Czech}$. The OHIP-14 scores were assessed in relation to chosen clinical and sociodemographic characteristics and oral health behaviour. Statistical analyses included descriptive analyses, the Mann-Whitney test, the Kolmogorov-S mirnov test and the Kruskal-Wallis test using the NCSS 2007 program. The $\chi^{2}$ test of independence in contingency tables or Fisher's exact test was used for qualitative data.

Results: Internal reliability for the 14 items overall was very high (Cronbach's $\alpha=0.924)$. The two most frequently scored items using the answer other than "never" during the last year were "painful aching" (62\% of subjects) and "uncomfortable to eat" (44.4\%), representing subdomain physical pain. The domain of social disability was reported least frequently. The OHIP-14 was significantly associated with dental status, dental behaviour, income and age.

Conclusions: The findings of this study do suggest that the culturally adapted OHIP-14 version may be a good research instrument to be considered for use in measuring the impact of oral problems on the quality of life in Czech population.
\end{abstract}

Key words: quality of life, oral health, oral health impact profile, oral health-related quality of life, questionnaire inquiry

Address for correspondence: L. Hodačová, Charles University in Prague, Faculty of Medicine, Department of Social Medicine, Šimkova 870, 50038 Hradec Králové, Czech Republic. E-mail: hodacoval@ Ifhk.cuni.cz

\section{INTRODUCTION}

Quality of life is a multidimensional concept that can be investigated from different points of view. Health and disease are apparently closely connected with the concept "quality of life". The increasing use of the terms "health-related quality of life" and "quality of life" in relation to the outcomes of health conditions and therapy for those conditions has been seen in medicine in the last 30 years (1). It is increasingly accepted that traditional clinical measures of health need to be suplemented by data concerning the experiences and concerns obtained from patients (2). Quality of life has been established as an important determinant of care seeking, adherence to treatment regimen, satisfaction with the care received and as an outcome for evaluating the impact of a disease and for assessing the efficacy of treatments $(1,3,4)$.

Oral diseases such as dental caries and periodontal disease are highly prevalent. There is a growing recognition that physical indicators of oral morbidity and the patient's perception of oral conditions contribute to the description of oral health status. The consequences of oral problems are not only physical, they are also economic, social and psychological. They seriously impair quality of life in a large number of individuals and can affect various aspects of life, including oral function, appearance, and interpersonal relationship (5-7). The outcome of oral health problems has been the subject of significant research activity over the last decade or so. Oral health-related quality of life is defined as an individual's assessment of how the following affect his or her wellbeing: functional factors, psychological factors, social factors, and experience of pain/discomfort in relation to orofacial concerns (8).

Assessment of oral health-related quality of life is vital for planning oral health programmes (9). Growing recognition of the importance regarding the relationship between a person's oral health and their quality of life in dentistry has led to the development of a variety of methods for measuring oral healthrelated quality of life $(6,10,11)$. Among them, one of the most comprehensive and the most used instrument available is the Oral Health Impact Profile (OHIP) and its short version OHIP-14 (11). The OHIP (12) was based on explicit conceptual framework and was derived from the accounts of dental patients with a variety of oral conditions $(11,13)$. It intends to assess the ,social impact“ of oral disorders, that is the dysfunction, discomfort and disability caused by these conditions (1). 
The aim of this study was to develop a Czech version of Oral Health Impact Profile (OHIP-14) and to assess the oral healthrelated quality of life in Czech population.

\section{METHODS}

This study that was approved by the Ethics Committee of Charles University in Prague, Faculty of Medicine in Hradec Králové, Czech Republic, and consisted of two parts: a self-reported questionnaire enquiry and clinical examination. Oral healthrelated quality of life was measured with OHIP-14 questionnaire that was translated to Czech. This study was part of broader three year study “The influence of smoking on oral health” supported by the Ministry of Health of Czech Republic. The second part of the study consisted of clinical examination done by dentists collaborating on the study. Dental status and periodontal status were assessed and documented for each of the respondent by DMFT (Decayed, Missing, and Filled Teeth) and CPITN (Community Periodondal Index of Treatment Needs) indices. The results of clinical examination are not part of this paper.

\section{Subjects}

The study was carried out on a sample of Czech adult population. The subjects consisted of patients attending the Department of Dentistry, Medical Faculty of Charles University in Hradec Králové, and also patients attending three private dental practitioners collaborating on the study. The inclusion criterion was age between 30 to 69 years. Total number of 1,474 respondents participated in the study. After excluding incomplete questionnaires (OHIP-14), a total of 1,380 questionnaires were considered for statistical analyses. Data were collected from March 2006 to September 2007. The participants were informed about the purpose of the study, and an informed consent was obtained. After the clinical examination, each participant was given instructions regarding dental treatment needs.

\section{Questionnaire}

The Oral Health Impact Profile (OHIP) is a technically sophisticated instrument that is widely used internationally $(4,12,14)$. It is one of the most commonly used instrument for measuring oral health-related quality of life and it was used to measure oral health-related quality of life in many countries that use English as a first language $(12,13,15-19)$. Several language versions already exist - e.g. German (20), Swedish (21), Chinese (22), Hebrew (23), Hungarian (24), Brazilian (25), etc. Although OHIP is a comprehensive and useful instrument, it is a long questionnaire with 49 items. Slade (26) derived and validated a short-form OHIP, which has been widely used in many studies (18, 27-31). In the Czech Republic, an oral health-related quality of life instrument currently does not exist. Therefore, it seemed obvious to crossculturally adapt the OHIP-14 in order to characterize the patients ‘ perception of oral health in the Czech population.

OHIP-14 consists of 14 items organized into 7 theoretical fields (functional limitation, pain, psychological discomfort, physical disability, psychological disability, social disability and handicap) (32). The OHIP-14 instrument is useful for quantifying levels of impact on well-being in a setting where only a limited number of questions can be used. The OHIP-14 includes two question items from each of the impact sub-domains. These domains are organized to reflect the hierarchy of increasingly complex and disruptive impacts or problems. The first three domains - functional limitations, physical pain and psychological discomfort - include items that are primarily limited to the individual's experience, whereas items in the disability and handicap domains represent impacts or problems that may alter everyday activity and social roles (33).

Frequency of troubles due to the oral problems mentioned in single items during the period of last 12 months is followed. The possible answers are (0 for "never”, 1 for "hardly ever”, 2 for “occasionally”, 3 for “fairly often”, and 4 for “very often”).

The OHIP-14 was translated into Czech to develop a version which was appropriate for the local population. The translation process involved forward translation from English into Czech by a bilingual individual whose first language was Czech and then the backward translation from Czech into English by another bilingual individual whose first language was English. In addition to the OHIP-14 questionnaire, subjects completed a self-administered questionnaire which requested information about personal history, economic status, educational level, profession, general health status, food habits, frequency of dental visits, brushing habits, alcohol consumption, cigarette smoking history and subjective assessment of oral health.

\section{Statistical Analysis}

Two ways were used for calculating OHIP-14 scores. Firstly, a simple counting of the number of items to which a subject responded "fairly often" or "very often" was performed. This reduced the response scale to a dichotomy and provided the number of functional and psychosocial impacts experienced on a yearly level. This method was called the simple-count method (OHIP-14 SC). Secondly, the numeric responses for all 14 items in each individual were counted (the numeric response codes were 0 for "never", 1 for "hardly ever", 2 for "occasionally", 3 for "fairly often", and 4 for "very often"). This method producing a single summative score for each respondent was called the sum OHIP-14. It incorporated the full range of impact responses, irrespective of their frequency. Internal consistency was assessed using Cronbach's reliability coefficient $\alpha$.

The OHIP-14 scores were assessed in relation to chosen clinical and sociodemographic characteristics and dental behaviour. Statistical analyses included descriptive analyses, the Mann-Whitney test, the Kolmogorov-Smirnov test and the Kruskal-Wallis test using the NCSS 2007 program. The $\chi^{2}$ test of independence in contingency tables or Fisher's exact test was used for qualitative data. The level of significance was $\alpha=0.05$.

\section{RESULTS}

The number of completed questionnaires was 1,380 (93.6\% of the total sample). Subjects who did not answer even one question were excluded from this statistical analyses $(n=94)$. The mean age of the subjects was $43.4 \pm 11.0$ years (range $30-69$ years); 652 (47.3\%) were males and 727 (52.7\%) were females. 
Table 1. Internal consistency of the Czech version OHIP-14 $(n=1380)$

\begin{tabular}{|l|c|}
\hline Domain & $\begin{array}{c}\text { Consistency } \\
\text { (Cronbach's coefficient } \alpha \text { ) }\end{array}$ \\
\hline Functional limitation & 0.60 \\
\hline Physical pain & 0.74 \\
\hline Psychological discomfort & 0.66 \\
\hline Physical disability & 0.84 \\
\hline Psychological disability & 0.63 \\
\hline Social disability & 0.73 \\
\hline Handicap & 0.67 \\
\hline Overall 14 questions & 0.92 \\
\hline
\end{tabular}

Cronbach's $\alpha$ coefficients for each of the seven health domains ranged from 0.6 (functional limitation) to 0.84 (physical disability), indicating good reliability for those dimensions. Internal reliability for the 14 items overall was very high $(\alpha=0.924)$ (Table 1$)$.

The impact of oral health to the quality of life was assessed with a simple counting of the number of items to which a subject responded 3 or 4 ("fairly often" and "very often" over the last year) (OHIP-14 SC). The mean of OHIP-14 SC was $0.43 \pm 1.46$ although the distribution ranged from 0 to 13 (Fig. 1). Only $14.8 \%$ of the subjects reported at least one oral health impact (fairly often or very often) over the last year, 1,176 persons (85.2\%) did not use value 3 or 4 for the answer and one person ( $0.2 \%)$ responded "fairly often" or "very often" in 13 out of 14 questions.

The percentage of people reporting an oral health impact answer "fairly often" or "very often" over the last year, the percentage of people reporting "never" and the percentage of people reporting any answer other than "never" for each item from the OHIP-14 questionnaire is shown in Table 2.

The percentage of subjects reporting an oral health impact for each item ranged from $8.6 \%$ (uncomfortable to eat) to $0.9 \%$ (un-



Fig. 1. Distribution of OHIP-14 SC (fairly often or very often).

able to function). The most prevalent, other than "never items" were those in sub-domain of physical pain (painful aching and uncomfortable to eat where $62 \%$ and $44.4 \%$ people reported other than "never" over the last year); the least prevalent other than “never items" were unable to function (12\%), trouble pronouncing words (13.3\%) and bad taste sensation (13.8\%).

Median for the sum OHIP-14 was 3; (the mean of the sumOHIP-14 was $5,42 \pm 7,55$ ) the first quartile was 0 ; the third quartile was 8 and the 90 th percentile was 14 . The distribution of the sum OHIP ranged from 0 to 51 (Fig. 2). Answer "never" in each item of the questionnaire was reported by 381 people $(27,6 \%)$ and the sum OHIP-14 was 51 in one person (0.1\%).

The bivariate analyses using the sum OHIP-14 and OHIP14 SC measures found statistically significant association with attitude to prevention $(\mathrm{p}<0.01)$, self-assessment of oral health $(\mathrm{p}<0.01)$, absence of own front tooth/teeth (sextant 2 , sextant 5 , sextant 2 and/or 5) $(\mathrm{p}<0.05)$, CPITN index (3 or 4$)(\mathrm{p}<0.01)$, frequency of toothbrushing $(\mathrm{p}<0.05)$, consumption of food or sweet liquids after evening toothbrushing $(\mathrm{p}<0.01)$, satisfaction with appearance of one's teeth $(\mathrm{p}<0.01)$, subjective comparison

Table 2. The percentage of subjects reporting to single items of the questionnaire

\begin{tabular}{|c|c|c|c|}
\hline Item number & $\begin{array}{c}\text { \% of people reporting 3 or 4 } \\
\text { (fairly often or often) }\end{array}$ & $\begin{array}{c}\text { \% of people reporting 0 } \\
\text { (never) }\end{array}$ & \% of people reporting other than 0 \\
\hline 1 & 1.9 & 86.7 & 13.3 \\
\hline 2 & 1.2 & 86.2 & 62.0 \\
\hline 3 & 7.7 & 38.0 & 44.4 \\
\hline 4 & 8.6 & 55.6 & 15.9 \\
\hline 5 & 1.4 & 84.1 & 21.6 \\
\hline 6 & 2.7 & 78.4 & 32.2 \\
\hline 7 & 4.1 & 67.8 & 24.3 \\
\hline 8 & 2.6 & 75.7 & 30.4 \\
\hline 9 & 3.3 & 69.6 & 14.1 \\
\hline 10 & 2.2 & 85.9 & 19.1 \\
\hline 11 & 1.6 & 80.9 & 14.5 \\
\hline 12 & 1.2 & 85.5 & 23.4 \\
\hline 13 & 3.6 & 76.6 & 12.0 \\
\hline 14 & 0.9 & 88.0 & \\
\hline
\end{tabular}




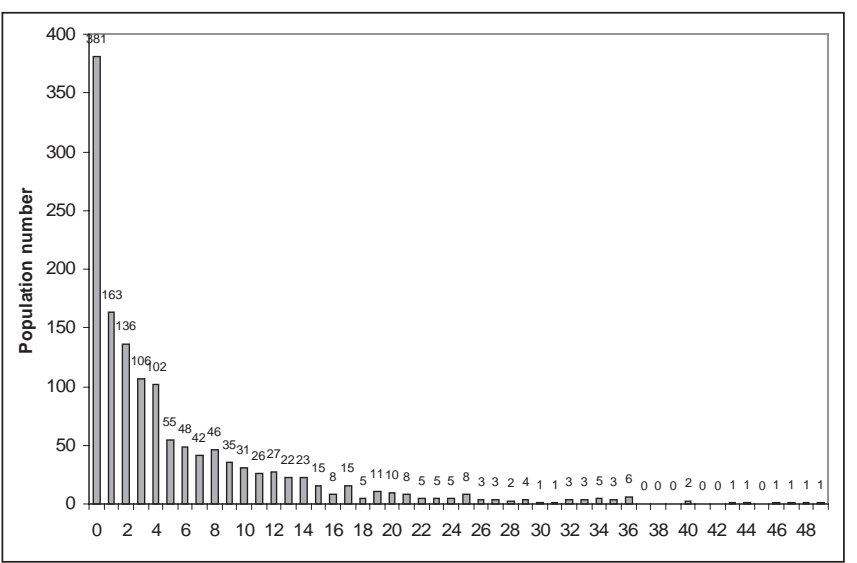

Fig. 2. Distribution of sum OHIP-14.

of one's oral health with others ( $<<0.01$ ), number of teeth (fewer than 25 and 25 and more $(\mathrm{p}<0.01)$ and general health $(\mathrm{p}<0.05)$. The statistically significant association in the sum OHIP-14 measure was also found with age $(\mathrm{p}<0.01)$, income $(\mathrm{p}<0.01)$, alcohol consumption (spirits) $(\mathrm{p}<0.05)$ and with smoking $(\mathrm{p}<0.01)$. In OHIP-14 SC significant association was found with education $(p<0.05)$. There were no significant difference in both scores by gender and alcohol consumption (beer, wine).

\section{DISCUSSION}

The patients، perception and their health-related quality of life have recently caught the attention of medical professionals, and this has lead to the rapid growth of research focusing on this area.

The perception and assessment of individual's health and health-related quality of life is to some extent culturally determined. It is therefore important to compare oral health related quality of life among different countries. Researchers who do not have a suitable health-related quality of life instrument available in their own language have two choices: a) to develop a new measure, or b) to modify a measure previously validated in another language, known as a cross-cultural adaptation process (33). The latter is more feasible in an international collaboration. The existing oral health-related quality of life instruments are adapted and used in other populations than in which they were originally tested (14). It was also found that cultural differences in subjects with own teeth do not play a role in the perception of oral problems to their quality of life. Therefore it is recommended to use some of the existing methods $(9,33,35)$. In the field of dentistry, the Oral Health Impact Profile (OHIP) has been developed to examine whether the oral problems of individuals affect their daily life. Several language versions already exist, and evidence for the instrument's cross-cultural equivalence is available (15). To date, a Czech version of the OHIP questionnaire have not been used.

While OHIP was intended to provide comprehensive data about the perception of well-being, our research setting was not suitable for using the full 49-item OHIP instrument. Therefore, we adapted the short-form OHIP-14, for which reliability, validity and precision also has been established (15). A short-form OHIP was developed to make the investigation on the oral health-related quality of life simpler and less time consuming (26). We developed OHIP-14 CZ for the same reason.

The aim of our study was to use the Czech version of the OHIP-14 questionnaire and to assess oral health-related quality of life on a sample of Czech population. The questionnaire was translated into Czech and its comprehensibility was tested within a pilot study on 200 patients (36). The Czech version OHIP-14 performed well with regard to reliability because of very high Cronbach's $\alpha$ value (0.92) for seven of the domains, suggesting that it is a useful instrument for measuring oral-health-related quality of life and that OHIP has international value.

The two most frequently scored items using the answer other than "never" during the last year were "painful aching” and "uncomfortable to eat", representing the subdomain physical pain. Other two most frequently scored items were from subdomain physical disability and psychological disability. The five items reported to occur most frequently in the last year as measured by the OHIP-14 SC were physical pain, physical disability, handicap and psychological disability. The domain of functional limitation and social disability were reported least frequently by both scoring methods.

When the results of our study were compared with those obtained in other countries $(15,22,33)$, it was interesting that the two most frequently reported items were from the subdomain physical pain. On the contrary to the other studies our respondents did not report items from subdomain psychological discomfort so frequently but they reported subdomain physical disability and psychological disability. It is also interesting that one of the items from the subdomain handicap (feeling that life was less satisfying because of problems with teeth, mouth or denture) was reported quite frequently (23.4\% subjects reported answer other than never during the last year). Locker's theoretical model of oral health indicate that social disability and handicap are less frequent and measure the most comprehensive impact on quality of life (37). The found differences can rise from the fact that Czech population is not accustomed to the self-assessment of general and oral health inquiries.

The OHIP-14 was significantly associated with dental status (number of teeth, absence of front tooth/teeth, CPITN index), dental behaviour (attitude to preventive check-ups, frequency of toothbrushing, consumption of food or sweet liquids after evening toothbrushing, alcohol consumption - spirits, smoking), and with general health. Income and age was found to be associated with the sum OHIP-14 measure and education was associated with OHIP-14 SC. There were no significant differences in both scores by gender, consumption of beer or wine.

The results of our research univocally point to the association between health behaviour and oral health-realted quality of life. One of the question that was assessed within our questionnaire was the attitude to the preventive check-ups. Preventive dental check-ups twice a year, covered by the health insurance in the Czech Republic had resulted in a higher percentage of respondents reporting regular preventive dental visits. The OHIP-14 scores were significantly lower in those who attended preventive check-ups twice a year compared to all other groups (preventive check-ups once a year, less often, or do not attend). However, as arise from our data that, only $66 \%$ of the sample reported regular twice a year visits for preventive check-ups, and 8\% attend 
preventive check-ups less than once in two years or never. The question remains unanswered on how to practically and effectively encourage our population to develop better attitude towards their health and to educate them about the importance of prevention. However, generalisation of the specific variables, which had an association in this study should be viewed with caution and not considered representative of the Czech population in general as our study population was a non-randomly-selected sample.

Familiarity with the precise data concerning presence or absence of a disease as well as the information about patients' own perception of their health are important for planning health preventive and promotive programmes. Patients' subjective assessment of their health-related quality of life is often different from the view of health professionals and that's why it is also important for assessing the efficacy of treatment interventions (9). Measurement of oral health is also important for ensuring public resources for dental care. The results of such researches enables the researchers in determining the specific needs of patients that need attention and help them in finding professional help.

The findings of this study do suggest that the culturally adapted OHIP-14 version may be a good research instrument to be considered for use in measuring the impact of oral problems on the quality of life in Czech population. Nevertheless, futher research is important.

\section{Acknowledgement}

This study was supported by Czech Ministry of Health Grant Agency, no: NR 8781-3/2006.

\section{REFERENCES}

1. Locker D, Allen F. What do measures of ,oral health-related quality of life“ measure? Community Dent Oral Epidemiol. 2007 Dec;35(6):40111.

2. Fitzpatrick R, Davey C, Buxton MJ, Jones DR. Evaluating patient-based outcome measures for use in clinical trials. Health Technol Assess. 1998;2(14):i-iv, 1-74.

3. Leplège $A$, Hunt $\mathrm{S}$. The problem of quality of life in medicine. JAMA. 1997 Jul 2;278(1):47-50.

4. Yamazaki M, Inukai M, Baba K, John MT. Japanese version of the Oral Health Impact Profile (OHIP-J). J Oral Rehabil. 2007 Mar;34(3):15968.

5. Locker D. Measuring oral health: a conceptual framework. Community Dent Health. 1988 Mar; 5(1): 3-18.

6. Naito M, Yuasa H, Nomura Y, Nakayama T, Hamajima N, Hanada N. Oral health status and health-related quality of life: a systematic review. J Oral Sci. 2006 Mar;48(1):1-7.

7. Hebling E, Pereira AC. Oral health-related quality of life: a critical appraisal of assessment tools used in elderly people. Gerontology. 2007 Sep;24(3):151-61.

8. Inglehart MR, Bagramian RA. Oral health-related quality of life: an introduction. In: Inglehart MR, Bagramian RA, editors. Oral health-related quality of life. Chicago: Quintessence Publishing; 2002. p. 1-6.

9. Allen PF. Assesment of oral health related quality of life. Health Qual Life Outcomes. 2003 Sep 8;1:40.

10. Corson MA, Boyd T, Kind P, Allen PF, Steele JG. Measuring oral health: does your treatment really make a difference. Br Dent J. 1999 Nov 13;187(9):481-4.

11. Bae KH, Kim HD, Jung SH, Park DY, Kim JB, Paik DI, et al. Validation of the Korean version of the oral health impact profile among the Korean elderly. Community Dent Oral Epidemiol. 2007 Feb;35(1):73-9.

12. Slade GD, Spencer AJ. Development and evaluation of the Oral Health Impact Profile. Community Dent Health. 1994 Mar;11(1):3-11.

13. Locker D, Slade G. Oral health and the quality of life among older adults: the oral health impact profile. J Can Dent Assoc. 1993 Oct;59(10):830-3, 837-8, 844.
14. Skaret E, Åstrøm AN, Haugejorden O. Oral Health Related Quality of Life (OHRQoL). Review of existing instruments and suggestions for use in oral health outcome research in Europe. In: Bourgeois DM, Llodra JC, editors. European Global Oral Health Indicators Development Project. Paris: Quintessence International; 2004. p. 99-110.

15. Slade GD, Spencer AJ, Locker D, Hunt RJ, Strauss RP, Beck JD. Variations in the social impact of oral conditions among older adults in South Australia, Ontario, and North Carolina. J Dent Res. 1996 Jul;75(7):1439-50.

16. Allison P, Locker D, Jokovic A, Slade G. A cross-cultural study of oral health values. J Dent Res. 1999 Feb;78(2):643-9.

17. Locker D, Matear D, Stephens M, Lawrence H, Payne B. Comparison of the GOHAI and OHIP-14 as measures of the oral health-related quality of life of the elderly. Community Dent Oral Epidemiol. 2001 Oct;29(5):373-81.

18. Steele JG, Sanders AE, Slade GD, Allen PF, Lahti S, Nuttall N, et al. How do age and tooth loss affect oral health impacts and quality of life? A study comparing national samples. Community Dent Oral Epidemiol. 2004 Apr;32(2):107-14.

19. Allen F, Locker D. A modified short version of the oral health impact profile for assessing health-related quality of life in edentulous adults. Int J Prothodont. 2002 Sep-Oct;15(5):446-50.

20. John MT, Patrick DL, Slade GD. The German version of the Oral Health Impact Profile-translation and psychometric properties. Eur J Oral Sci. 2002 Dec;110(6):425-33.

21. Larsson P, List T, Lundström I, Marcusson A, Ohrbach R. Reliability and validity of a Swedish version of the Oral Health Impact Profile (OHIP-S). Acta Odontol Scand. 2004 Jun;62(3):147-52.

22. Wong MC, Lo EC, McMillan AS. Validation of a Chinese version of the Oral Health Impact Profile (OHIP). Community Dent Oral Epidemiol. 2002 Dec;30(6):423-30.

23. Kushnir D, Zusman SP, Robinson PG. Validation of a Hebrew version of the Oral Health Impact Profile - 14. J Publc Health Dent. 2004;64(2):71-5.

24. Szentpétery A, Szabó G, Marada G, Szántó I, John MT. The Hungarian version of the J Oral Health Impact Profile. Eur J Oral Sci. 2006 Jun;114(3):197-203.

25. Souza RF, Patrocínio L, Pero AC, Marra J, Compagnoni MA. Reliability and validation of a Brazilian version of the Oral Health Impact Profile for assessing edentulous subjects. J Oral Rehabil. 2007 Nov;34(11):821-6.

26. Slade GD. Derivation and validation of a short-form oral health impact profile. Community Dent Oral Epidemiol. 1997 Aug;25(4):284-90.

27. Heydecke G, Tedesco LA, Kowalski C, Inglehart MR. Complete dentures and oral health-related quality of life - do coping styles matter? Community Dent Oral Epidemiol. 2004 Aug;32(4):297-306.

28. Locker D, Jokovic A, Clarke M. Assessing the responsiveness of measures of oral health-related quality of life. Community Dent Oral Epidemiol. 2004 Feb;32(1):10-8.

29. Ng SK, Leung WK. Oral health-relatd quality of life and periodontal status. Community Dent Oral Epidemiol. 2006 Apr;34(2):114-22.

30. Fernandes MJ, Ruta DA, Ogden GR, Pitts NB, Ogston SA. Assessing oral health-related quality of life in general dental practice in Scotland: validation of the OHIP-14. Community Dent Oral Epidemiol. 2006 Feb;34(1):53-62.

31. John MT, Miglioretti DL, LeResche L, Koepsell TD, Hujoel P, Micheelis W. German short forms of the Oral Health Impact Profile. Community Dent Oral Epidemiol. 2006 Aug;34(4):277-88.

32. John MT, Hujoel P, Miglioretti DL, LeResche L, Koepsell TD, Micheelis W. Dimensions of oral-health-related quality of life. J Dent Res. 2004 Dec;83(12):956-60.

33. Ikebe K, Watkins CA, Ettinger RL, Sajima H, Nokubi T. Application of short-form oral health impact profile on elderly Japanese. Gerontology. 2004 Sep;21(3):167-76.

34. Allen PF, McMillan AS, Locker D. An assessment of sensitivity to change of the Oral Health Impact Profile in a clinical trial. Community Dent Oral Epidemiol. 2001 Jun;29(3):175-82.

35. Astrøm AN, Haugejorden O, Skaret E, Trovik TA, Klock KS. Oral impacts affecting Daily Performance in Norwegien adults: validity, reliability and prevalence estimates. Eur J Oral Sci. 2005 Aug;113(4):289-96.

36. Hodačová L, Šmejkalová J, Čermáková E, Slezák R, Mareš J. Assessing oral health-related quality of life in Czech population. Prak Lek. 2007 Jul;87(7):421-5. (In Czech.)

37. Locker D. Measuring oral health: a conceptual framework. Community Dent Health. 1988 Mar;5(1):3-18. 